\title{
Relações de convivência e princípios de justiça: a educação moral na escola
}

\author{
Glycia Melo de Oliveira \\ Iraquitan de Oliveira Caminha \\ Clara Maria Silvestre Monteiro de Freitas
}

\begin{abstract}
Resumo
A moral está associada aos valores humanos e às relações de convivência que nutrem a construção do juízo moral. Diante de tais evidências, este estudo propõe-se a revisar a literatura em torno da moralidade, permeada pelas relações de convivência no espaço escolar, buscando estabelecer a relação entre o saber conviver, a apropriação de valores e a compreensão da noção de justiça no espaço escolar. Estabeleceremos tais relações buscando, a partir dos estudos selecionados, refletir sobre a seguinte questão: Em que medida a educação moral tem sido considerada no processo educacional do educando na escola? O método utilizado foi a revisão sistemática, sendo selecionados 21 artigos que discorrem sobre a moralidade na escola, publicados em forma de texto completo entre o período de janeiro de 2000 e maio de 2009 . Pôde-se identificar a preocupação existente nos estudos quanto à urgência em problematizar a educação moral na escola, enfocando a importância de se efetivar práticas com os atores envolvidos no cenário escolar e despertando nos alunos o desejo de se tornarem sujeitos morais e de contribuírem para a construção de um mundo mais tolerante e justo.
\end{abstract}

Palavras-chave: Educação moral, escolas, convivência.

\section{Relations of sociability and justice's principles: moral education in school}

\begin{abstract}
Moral is associated with human values and relations of sociability that nourish the construction of moral judgments. Due those evidences, this study aims to review the literature around morality, permeated by relations of coexistence within the school, seeking to establish the relationship between knowing how to live, the appropriation of values and sociability and justice's principles in school setting. Seeking to establish such relationships, based on selected studies reflect the following question: To what extent does moral education has been considered in the educational process of the student in school? The method used was a systematic review by selecting 21 articles that talk about morality in schools, published in full text form from the period January 2000 to May 2009. Existing study concern could be identified in regarding the urgency to confront the moral education in school, focusing on the importance of developing practices with the actors involved in the school setting, raising the students' desire to become moral subjects and contribute to construction of a more tolerant and fair world.
\end{abstract}

Key-words: Moral education, schools, coexistence.

\section{Relaciones de convivencia y principios de justicia: la educación moral en la escuela}

\begin{abstract}
Resumen
La moral está asociada a los valores humanos y a las relaciones de convivencia que nutren la construcción del juicio moral. Frente a tal evidencia, este estudio propone revisar la literatura acerca de la moralidad permeada por las relaciones de convivencia en el espacio escolar, buscando establecer la relación entre el saber convivir, la apropiación de valores y la comprensión de la noción de justicia en el mismo espacio. Estableceremos esas relaciones buscando, a partir de los estudios seleccionados, reflexionar la siguiente interrogante: ¿En qué medida la educación moral ha sido considerada en el proceso educacional del educando en la escuela? El método utilizado fue la revisión sistemática, siendo seleccionados 21 artículos que disertan sobre la moralidad en la escuela, publicados en forma de texto completo entre el período de enero de 2000 y mayo de 2009. Se pudo identificar la preocupación existente en los estudios en relación a la urgencia en problematizar la educación moral en la escuela, enfocando la importancia de realizarse prácticas con los actores involucrados en el escenario escolar, despertando e $\mathrm{n}$ los alumnos el deseo de tornarse sujetos morales y de contribuir para la construcción de un mundo más tolerante y justo.
\end{abstract}

Palabras- clave: Educación moral, escuelas, convivencia. 


\section{Introdução}

A moral está associada à apropriação de valores humanos e às relações de convivência que nutrem a construção do juízo moral. Destacar a importância de discussões em torno da moralidade no mundo contemporâneo significa considerar o acentuado individualismo, consumismo e competitividade entre as pessoas que esse cenário atual provoca, de modo que dificulta a instauração do bem comum, da solidariedade e da justiça social como foco das preocupações políticas e sociais (Estêvão, 2008).

Os sujeitos trazem tatuadas nos corpos marcas das normas, regras e valores de uma dada sociedade como expressão da cultura (Daolio, 1995). Isso significa que a formação humana constitui-se a partir dos costumes, condutas, ações e atitudes, embasadas em valores, mediante experiências e aprendizagens que se desenvolvem no cenário das relações familiares, sociais e midiáticas (Goergen, 2007; Souza, 2005).

Nesse sentido, a escola deve exercer um papel fundamental nas discussões em torno da moralidade. Essa instituição educacional foi constituída, ao longo do tempo, cumprindo o papel de transmissão-assimilação de conteúdos tradicionais e desconsiderando, muitas vezes, o aspecto sociocultural impregnado no cotidiano escolar. Diante das inúmeras transformações e exigências que o novo século provoca, este artigo tem como propósito refletir sobre o espaço escolar como um espaço voltado à educação moral, um espaço de convivência que, com o compartilhar com o outro, possibilite a aquisição de valores morais formadores de sujeitos éticos e solidários.

Um dos principais autores que trata a questão da formação do juízo moral nas crianças é Jean Piaget. Para ele, o desenvolvimento da moralidade se dá principalmente através da atividade de cooperação, do contato com iguais, da relação com companheiros, do reconhecimento e respeito às diferenças (Piaget, 1994). Nesse sentido, a escola constitui-se em um espaço privilegiado para a criança conviver com outras da mesma faixa etária e para focar reflexões voltadas à moralidade.

Piaget (1994) associa as fases do desenvolvimento cognitivo humano (período sensório-motor, pré-operacional, operacional concreto e operacional formal) com a aquisição da moralidade a partir da maturidade da criança e, consequentemente, sua capacidade cognitiva de compreender, discernir e julgar as regras. Isso significa que a moralidade constitui-se gradativamente com a maturidade do indivíduo, ou seja, a formação moral compreende fases que se constituem de acordo com o nível de maturidade da criança. As fases do desenvolvimento moral, baseadas na teoria de Piaget, compreendem dois tipos de moral: a moral heterônoma e a moral autônoma.

A moral heterônoma constitui-se, aproximadamente, dos dois aos cinco anos de idade e engloba o estágio voltado a ações mediadas pelo egocentrismo da criança. Nessa fase, estabelece-se uma relação intercedida pela coação moral da autoridade dos pais e/ou adultos. A validade das regras para a criança tem valor exterior a elas, ou seja, está associada à vontade ou "ordem" de quem provém. A criança considera as regras como supremas, imutáveis, "sagradas" e, por isso, concebe que devem ser cumpridas e jamais modificadas. Segundo Piaget, a fase da moral heterônoma é fundamental para o desenvolvimento moral do sujeito, uma vez que ela constitui-se numa fase essencial para que a etapa subsequente possa germinar em formas superiores de respeito aos valores morais.

À medida que as trocas sociais são estabelecidas, surge um novo tipo de interação social que Piaget denomina como a fase da Cooperação Nascente, o que implica na substituição de atitudes egocêntricas por atitudes cooperativas. Essa fase é marcada pelo início da moral autônoma, por volta dos sete ou oito anos de idade, e baseia-se no princípio da igualdade, no respeito mútuo e nas relações de convivência. Esse tipo de moral é caracterizado pela colaboração igualitária, cujo respeito mútuo é fator preponderante, o que implica em respeitar e ser respeitado.

Seguindo, então, a compreensão acerca do desenvolvimento moral da criança, a teoria piagetiana defende que o espírito de punição realizado pelas crianças demonstra fases que acompanham os estágios da moralidade. De acordo com os resultados obtidos por Piaget (1994), em sua clássica obra sobre o juízo moral nas crianças, há duas tendências no julgamento infantil: julgamento por responsabilidade objetiva e por responsabilidade subjetiva.

O julgamento por responsabilidade objetiva está associado à justiça retributiva. Esse tipo de justiça diz respeito à fase da coação moral, do sentimento de dever, da moral heterônoma, quando a criança julga um ato não pela intencionalidade que o presidiu, mas por suas consequências. Interpreta as regras ao pé da letra e não no contexto nas quais estão inseridas; quando a criança encontra-se nessa fase, julga que o essencial é punir o culpado pela consequência material direta de sua falta. Enquanto que o julgamento por responsabilidade subjetiva diz respeito à justiça distributiva, fase da moral autônoma, das relações de cooperação, do sentimento do bem. A criança passa a considerar a intenção em que um dado ato é vivido, julgando de acordo com o igualitarismo e a equidade, a fim de que o culpado compreenda o alcance dos seus atos (Piaget, 1994; Brasil, 1997). Então, para que se compreenda o juízo moral infantil, é preciso que o valor de uma punição julgada pela criança transite de uma medida fundada na sua severidade, considerando a materialidade do ato, para uma medida fundada na intenção do sujeito que cometeu o ato, considerando as circunstâncias em que o ato ocorreu.

É válido ressaltar que há uma fase de transição entre esses dois tipos de justiça, pela qual é possível identificar características tanto de uma fase quanto de outra, revelando, assim, um mero e estrito igualitarismo (Diaz-Aguado \& Medrano, 1999).

Dessa forma, Piaget (1994) considera três grandes períodos no desenvolvimento da justiça na criança:

um período estendendo-se até mais ou menos sete-oito anos, durante o qual a justiça está subordinada à autoridade 
adulta, um período compreendido entre oito-onze anos aproximadamente, que é o do igualitarismo progressivo, e finalmente um período que se inicia por volta dos onzedoze anos, durante o qual a justiça puramente igualitária é temperada pelas preocupações de equidade (p.236).

A teoria piagetiana leva-nos a acreditar que oportunidades educativas em que se cultivem os valores e permitam aos sujeitos refletirem suas condutas são essenciais para a construção de sujeitos morais. Ninguém nasce com uma moral já constituída. Nesse sentido, compreendemos a escola como um espaço privilegiado para oferecer tais oportunidades.

Assim, diante das evidências quanto à necessidade de se sistematizar práticas educativas voltadas para a formação de sujeitos morais, este estudo propõe-se a revisar a literatura em torno da moralidade permeada pelas relações de convivência, buscando estabelecer uma relação entre o saber conviver, a apropriação de valores e a compreensão de justiça no espaço escolar. Estabeleceremos tais relações buscando, a partir dos estudos selecionados, refletir sobre a seguinte questão: Em que medida a educação moral tem sido considerada no processo educacional do educando na escola?

\section{Método}

A metodologia utilizada foi a revisão sistemática, a qual consiste em selecionar criticamente pesquisas consideradas relevantes acerca da temática em pauta.

A revisão sistemática aqui realizada consistiu na busca de artigos em bases de dados eletrônicas da Biblioteca Virtual em Saúde (Bireme), especificamente na Literatura Latino-Americana e do Caribe em Ciências da Saúde (Lilacs) e na Scientific Eletronic Library Online (Scielo). Foram incluídos artigos originais que apresentaram discussões em torno da temática proposta, ou seja, que estabeleceram relações com a moralidade, com as relações de convivência e com a compreensão de justiça no cenário escolar. Além disso, os artigos selecionados deveriam ter, como base, análise de dados coletados no Brasil, que estivessem publicados em forma de texto completo entre janeiro de 2000 e maio de 2009. Justifica-se a escolha desse período histórico como uma tentativa de trazer à tona uma discussão atual sobre a educação moral, destacando a primeira década de segundo milênio de nossa era.

Iniciamos a busca a partir da combinação de três grupos de dois diferentes descritores para, posteriormente, combinar os resultados obtidos. Assim, o primeiro grupo estabeleceu-se pelos descritores criança, moral, resultando em 1413 artigos; o segundo grupo, pelos descritores valores sociais, moral, resultando em 91 artigos; e o terceiro grupo pelos descritores escola, moral, resultando em 25 artigos. Foram excluídos os artigos repetidos em mais de um grupo, bem como aqueles que não contemplavam os critérios de inclusão considerados nesse estudo. A partir desse procedimento, obtivemos 21 artigos selecionados e analisados criticamente.

\section{Resultados}

A partir da combinação dos descritores, foram identificados 21 artigos que preencheram os critérios de inclusão. Os quadros a seguir, divididos por periódicos de publicação, trazem um panorama dos artigos pesquisados, possibilitando, ao leitor, compreender a caracterização da pesquisa, incluindo os instrumentos utilizados, bem como a localidade em que foram realizadas as referidas pesquisas. Nos casos em que a pesquisa é de cunho teórico, consideramos a cidade da revista em que o artigo foi publicado.

Foi observada a predominância de artigos de cunho teórico $(57,2 \%)$, o que nos faz acreditar que a educação moral precisa abarcar o cenário escolar com maior expressividade quanto à efetivação e democratização de práticas pedagógicas que fomentem a experiência, discussão e vivência prática em torno de valores morais, havendo, assim maiores possibilidades de pesquisas de campo $(42,8 \%)$ que sustentem e complementem a fundamentação teórica que trata da educação moral. Não queremos desmerecer a essencial importância da pesquisa teórica, mas demarcar a necessidade em efetivar projetos pedagógicos que sistematizem práticas educativas focadas na formação de sujeitos morais, contribuindo na construção de uma sociedade mais justa, solidária e ética.

Além disso, observamos grande disparidade nas regiões $^{1}$ do Brasil em que os estudos foram realizados ou naquelas correspondentes aos periódicos dos artigos pesquisados, sendo evidenciada maior concentração na região Sudeste (66,7\%). A região Sul obteve 19\% das produções; a Centro-Oeste, 9,5\% e a região Nordeste obteve apenas $4,8 \%$ do total dos artigos pesquisados. Destacamos que não houve nenhum artigo selecionado referente à região Norte do país. Observamos também a concentração dos artigos selecionados em periódicos da mesma natureza, sendo 23,8\% na Revista Psicologia: Reflexão e Crítica (Quadro 1); $19 \%$ na Educação e Sociedade (Quadro 2); 9,5\% na Psicologia da Educação (Quadro 3); 9,5\% na Psicologia escolar e educacional (Quadro 4); e apenas 4,8\% em cada uma das demais revistas: Psicologia: ciência e profissão (Quadro 5), Psicologia: teoria e pesquisa (Quadro 6), Avaliação e políticas públicas em educação (Quadro 7), Revista Educação Especial (Quadro 8), Paidéia - Ribeirão Preto (Quadro 9), Psicologia: revista da Vetor editora (Quadro 10), Educação: teoria e prática (Quadro 11) e Revista crítica de Ciências Sociais e Humanas (Quadro 12).

Pudemos identificar a preocupação existente nos estudos revisados quanto à urgência em problematizar a educação moral na escola, destacando a importância de efetivar práticas com os atores envolvidos no cenário escolar para despertar nos alunos o desejo de se formarem sujeitos morais, contribuindo para a construção de um mundo mais tolerante e justo.

1 Dado referente à localidade (cidade/Estado) em que ocorreu a pesquisa. 
Quadro 1. Artigos do periódico Psicologia: Reflexão e Crítica.

\begin{tabular}{|c|c|c|c|c|}
\hline AUTOR/ ANO & PERIÓDICO & MÉTODO/ INSTRUMENTOS & PALAVRAS-CHAVE & LOCALIDADE \\
\hline Sales (2000) & $\begin{array}{c}\text { Psicologia: Reflexão } \\
\text { e Crítica }\end{array}$ & $\begin{array}{l}\text { Pesquisa de campo; } \\
\text { Entrevista }\end{array}$ & $\begin{array}{c}\text { Psicologia; } \\
\text { desenvolvimento } \\
\text { sociomoral; justiça } \\
\text { distributiva; igualdade; } \\
\text { equidade }\end{array}$ & Três Lagoas- MS \\
\hline $\begin{array}{l}\text { Dell"Aglio e Hutz } \\
\text { (2001) }\end{array}$ & $\begin{array}{c}\text { Psicologia: Reflexão } \\
\text { e Crítica }\end{array}$ & $\begin{array}{l}\text { Pesquisa de campo; } \\
\text { Mini-histórias }\end{array}$ & $\begin{array}{c}\text { Justiça distributiva; } \\
\text { equidade; } \\
\text { igualdade }\end{array}$ & Porto Alegre- RS \\
\hline La Taille (2006) & $\begin{array}{c}\text { Psicologia: Reflexão } \\
\text { e Crítica }\end{array}$ & $\begin{array}{c}\text { Pesquisa de campo; } \\
\text { Entrevista (histórias contadas) }\end{array}$ & $\begin{array}{c}\text { Moral; generosidade; } \\
\text { justiça; desenvolvimento }\end{array}$ & São Paulo- SP \\
\hline Dias (2005) & $\begin{array}{c}\text { Psicologia: Reflexão } \\
\text { e Crítica }\end{array}$ & $\begin{array}{c}\text { Pesquisa de campo; } \\
\text { Entrevista semiestruturada }\end{array}$ & $\begin{array}{l}\text { Autonomia; educação } \\
\text { moral; educação infantil }\end{array}$ & Niterói- RJ \\
\hline $\begin{array}{l}\text { Sampaio, Camino } \\
\text { e Roazzi (2007) }\end{array}$ & $\begin{array}{c}\text { Psicologia: Reflexão } \\
\text { e Crítica }\end{array}$ & $\begin{array}{c}\text { Pesquisa de campo; } \\
\text { Entrevista (histórias dilema) }\end{array}$ & $\begin{array}{l}\text { Justiça distributiva; } \\
\text { desenvolvimento; } \\
\text { igualdade; equidade }\end{array}$ & Campina Grande- PB \\
\hline
\end{tabular}

Quadro 2. Artigos do periódico Educação e Sociedade.

\begin{tabular}{|c|c|c|c|c|}
\hline AUTOR/ ANO & PERIÓDICO & MÉTODO/ INSTRUMENTOS & PALAVRAS-CHAVE & LOCALIDADE \\
\hline Oliveira (2001) & $\begin{array}{c}\text { Educação e } \\
\text { Sociedade }\end{array}$ & Pesquisa teórica & $\begin{array}{c}\text { Ética na escola; } \\
\text { formação do caráter; } \\
\text { princípios éticos/morais; } \\
\text { argumentação, Parâmetros } \\
\text { Curriculares Nacionais }\end{array}$ & Campinas-SP \\
\hline Goergen (2001) & $\begin{array}{c}\text { Educação e } \\
\text { Sociedade }\end{array}$ & Pesquisa teórica & $\begin{array}{c}\text { Educação moral; Ética; } \\
\text { valores; subjetividade; } \\
\text { pluralidade }\end{array}$ & Campinas-SP \\
\hline Goergen (2005) & $\begin{array}{c}\text { Educação e } \\
\text { Sociedade }\end{array}$ & Pesquisa teórica & $\begin{array}{c}\text { Valores; Ética; educação } \\
\text { moral; sujeito moral; agir } \\
\text { comunicativo }\end{array}$ & Campinas-SP \\
\hline Goergen (2007) & $\begin{array}{c}\text { Educação e } \\
\text { Sociedade }\end{array}$ & Pesquisa teórica & $\begin{array}{c}\text { Educação moral; formação } \\
\text { de professores; justiça } \\
\text { social }\end{array}$ & Campinas-SP \\
\hline
\end{tabular}

Quadro 3. Artigos do periódico Psicologia da Educação.

\begin{tabular}{|c|c|c|c|c|}
\hline AUTOR/ ANO & PERIÓDICO & MÉTODO/ INSTRUMENTOS & PALAVRAS-CHAVE & LOCALIDADE \\
\hline Gonçalves (2004) & $\begin{array}{c}\text { Psicologia da } \\
\text { Educação }\end{array}$ & Pesquisa teórica & $\begin{array}{c}\text { Identidade do Eu, } \\
\text { desenvolvimento moral, } \\
\text { autonomia }\end{array}$ & São Paulo- SP \\
\hline Montenegro (2005) & $\begin{array}{c}\text { Psicologia da } \\
\text { Educação }\end{array}$ & Pesquisa teórica & $\begin{array}{c}\text { Creche; Pré-escola; } \\
\text { Psicologia moral }\end{array}$ & São Paulo- SP \\
\hline
\end{tabular}


Quadro 4. Artigos do periódico Psicologia Escolar e Educacional.

\begin{tabular}{|c|c|c|c|c|}
\hline AUTOR/ ANO & PERIÓDICO & MÉTODO/ INSTRUMENTOS & PALAVRAS-CHAVE & LOCALIDADE \\
\hline $\begin{array}{c}\text { Palmieri e Branco } \\
(2007)\end{array}$ & $\begin{array}{c}\text { Psicologia Escolar e } \\
\text { Educacional }\end{array}$ & Pesquisa de campo & $\begin{array}{c}\text { Cooperação, competição, } \\
\text { individualismo }\end{array}$ & Londrina- PR \\
\hline $\begin{array}{c}\text { Beluci e Shimizu } \\
(2007)\end{array}$ & $\begin{array}{c}\text { Psicologia escolar e } \\
\text { educacional }\end{array}$ & $\begin{array}{c}\text { Pesquisa de campo; } \\
\text { Questionário }\end{array}$ & $\begin{array}{c}\text { Desenvolvimento moral; } \\
\text { aprendizagem; ambiente } \\
\text { escolar }\end{array}$ & Campinas- SP \\
\hline
\end{tabular}

Quadro 5. Artigo do periódico Psicologia: Ciência e Profissão.

\begin{tabular}{|c|c|c|c|c|}
\hline AUTOR/ ANO & PERIÓDICO & MÉTODO/ INSTRUMENTOS & PALAVRAS-CHAVE & LOCALIDADE \\
\hline Sampaio (2007) & $\begin{array}{c}\text { Psicologia: Ciência e } \\
\text { Profissão }\end{array}$ & Pesquisa teórica & $\begin{array}{c}\text { Moralidade; Psicologia; } \\
\text { Educação }\end{array}$ & Brasília- DF \\
\hline
\end{tabular}

Quadro 6. Artigo do periódico Psicologia: Teoria e Pesquisa.

\begin{tabular}{|c|c|c|c|c|}
\hline AUTOR/ ANO & PERIÓDICO & MÉTODO/ INSTRUMENTOS & PALAVRAS-CHAVE & LOCALIDADE \\
\hline $\begin{array}{c}\text { Tognatta e La Taille } \\
(2008)\end{array}$ & $\begin{array}{c}\text { Pesquisa de campo; } \\
\text { Puestionário escrito (histórias } \\
\text { contadas), testes estatísticos: } \\
\text { pesquisa } \\
\text { teste exato de Fisher, teste Qui- } \\
\text { quadrado, teste Stuart-Maxwell } \\
\text { e a Análise de Correspondência } \\
\text { Múltipla }\end{array}$ & $\begin{array}{c}\text { Ética; Moral; generosidade; } \\
\text { emopresentações } \\
\text { de si. }\end{array}$ \\
\hline
\end{tabular}

Quadro 7. Artigo do periódico Ensaio: Avaliação e Políticas Públicas em Educação.

\begin{tabular}{|c|c|c|c|c|}
\hline AUTOR/ ANO & PERIÓDICO & MÉTODO/ INSTRUMENTOS & PALAVRAS-CHAVE & LOCALIDADE \\
\hline Estevão (2008) & $\begin{array}{c}\text { Ensaio: Avaliação e } \\
\text { Políticas Públicas em } \\
\text { Educação }\end{array}$ & Pesquisa teórica & $\begin{array}{c}\text { Educação; conflito; } \\
\text { convivência }\end{array}$ & Rio de Janeiro- RJ \\
\hline
\end{tabular}

Quadro 8. Revista Educação Especial.

\begin{tabular}{|c|c|c|c|c|}
\hline AUTOR/ ANO & PERIÓDICO & MÉTODOI INSTRUMENTOS & PALAVRAS-CHAVE & LOCALIDADE \\
\hline Rosseto (2008) & $\begin{array}{c}\text { Revista Educação } \\
\text { Especial }\end{array}$ & Pesquisa teórica & $\begin{array}{c}\text { Educação; pensamento } \\
\text { sistêmico; sujeito }\end{array}$ & Santa Maria- RS \\
\hline
\end{tabular}


Quadro 9. Artigo do periódico Paideia- Ribeirão Preto

\begin{tabular}{|c|c|c|c|c|}
\hline AUTOR/ ANO & PERIÓDICO & MÉTODO/ INSTRUMENTOS & PALAVRAS-CHAVE & LOCALIDADE \\
\hline Fischmann (2007) & $\begin{array}{c}\text { Paideia- Ribeirão } \\
\text { Preto }\end{array}$ & Pesquisa teórica & $\begin{array}{c}\text { Diversidade; Direitos } \\
\text { humanos; autonomia } \\
\text { moral; minorias; Educação }\end{array}$ & Ribeirão Preto- SP \\
\hline
\end{tabular}

Quadro 10. Artigo do periódico Psicologia: Revista da Vetor Editora

\begin{tabular}{|c|c|c|c|c|}
\hline AUTOR/ ANO & PERIÓDICO & MÉTODO/ INSTRUMENTOS & PALAVRAS-CHAVE & LOCALIDADE \\
\hline Vale e Alencar (2008) & $\begin{array}{c}\text { Psicologia: Revista da } \\
\text { Vetor Editora }\end{array}$ & $\begin{array}{c}\text { Pesquisa de campo; } \\
\text { Entrevista (história-dilema) }\end{array}$ & $\begin{array}{c}\text { Juízo moral; generosidade; } \\
\text { punição. }\end{array}$ & Vitória- ES \\
\hline
\end{tabular}

Quadro 11. Artigo do periódico Educação: Teoria e Prática

\begin{tabular}{|c|c|c|c|c|}
\hline AUTOR/ ANO & PERIÓDICO & MÉTODO/ INSTRUMENTOS & PALAVRAS-CHAVE & LOCALIDADE \\
\hline Salles et al.(2008) & $\begin{array}{c}\text { Educação: Teoria e } \\
\text { Prática }\end{array}$ & Pesquisa teórica & $\begin{array}{c}\text { Preconceitos; violência; } \\
\text { escola }\end{array}$ & Rio Claro- SP \\
\hline
\end{tabular}

Quadro 12. Artigo do periódico Caesura:Revista Crítica de Ciências Sociais e Humanas

\begin{tabular}{|c|c|c|c|c|}
\hline AUTOR/ ANO & PERIÓDICO & MÉTODO/ INSTRUMENTOS & PALAVRAS-CHAVE & LOCALIDADE \\
\hline Oliveira (2005) & $\begin{array}{c}\text { Caesura: } \\
\text { Revista Crítica de } \\
\text { Ciências Sociais e } \\
\text { Humanas }\end{array}$ & Pesquisa teórica & $\begin{array}{c}\text { Ética; convivência; } \\
\text { educação ética }\end{array}$ & Canoas- RS \\
\hline
\end{tabular}

\section{Discussão}

\section{Convivência e Educação Moral}

As interações sociais são essenciais para o desenvolvimento moral, pois contribuem para que os sujeitos se descentrem cognitivamente e considerem a realidade a partir dos pontos de vista de outras pessoas (Sampaio, 2007). Pensamos que a escola constitui-se em espaço privilegiado para as crianças desfrutarem situações distintas na tarefa de aprender a conviver, a fim de serem capazes de viver em sociedade.

Considerar a escola como espaço pertinente às relações de convivência implica em aperfeiçoar as relações humanas em prol da construção coletiva da vida em sociedade, sendo, assim, imprescindível saber conviver, acolher o outro enquanto outro, considerando-o como semelhante e, ao mesmo tempo, diferente (Caminha, 2007).

Ao tratar o papel da escola em torno da educação moral e das relações de convivência, Fischmann (2007) relaciona a autonomia moral dos indivíduos no interior de organizações, em especial a escola, com a construção democrática, a partir do debate da relação entre diversidade e direitos humanos. Destaca que, ao se pretender a democracia e o respeito aos direitos humanos como construção cotidiana, o indivíduo deveria conviver com a justiça e com a possibilidade de mudar, longe da sombra ilusória e opressora do inevitável.

Para Estevão (2008), a escola precisa ser potencializadora da convivencialidade democrática, estimulando o aluno a perceber o outro não como um rival, mas como um indivíduo com que se deve colaborar, que o ajuda a crescer e que, ao ajudar o próximo, sente-se essencialmente mais feliz.

Rossetto (2008), em estudo sobre o pensamento de Maturana, destaca o quanto este biólogo enfatiza a im- 
portância não só de aspectos biológicos, mas também dos aspectos sociais e culturais para se pensar as relações de convivência entre os seres humanos. Para ele, a educação constitui-se em um processo de transformação na e pela convivência com o outro e consigo mesmo, contemplando um espaço de aceitação recíproca, em que haja o respeito e a compreensão entre os sujeitos.

Com isso, o educar constitui-se na integração de um indivíduo com o outro, de forma que, ao conviver com o outro, haja uma transformação espontânea; o modo de viver se faz progressivamente mais congruente com o do outro no espaço de convivência (Rossetto, 2008). Nesse sentido, não cabe mais à escola pensar o ato educativo como mera transmissão de conteúdos acadêmicos, renegando os saberes oriundos da convivência entre os sujeitos.

A escola precisa oportunizar aos alunos a vivência de valores desabrochados nas relações de convivência, o que significa desenvolver projetos em prol da educação moral. Tematizar a educação moral não significa promover a "internalização mecânica ou literal de normas" (Goergen, 2001, p.04). Nesse contexto, não cabe à escola introduzir preceitos morais como regras absolutas, mas conduzir o aluno ao mundo do agir moral por um processo pedagógico/reflexivo/comunicativo, posto que as normas sejam percebidas como parâmetro mínimo necessário das relações de convivência humana, do respeito à vida e da dignidade humana (Goergen, 2001).

Este pensamento reforça o salutar papel da escola para a construção de uma sociedade mais ética, solidária e justa. Diante de uma sociedade marcada pela intolerância, precisamos propagar nossas vozes em prol da necessidade da educação moral no âmbito da escola.

A escola, ao constituir-se em uma das principais instituições responsáveis pela formação dos indivíduos, revela-se como um espaço por excelência em que o sujeito deve ter possibilidades de vivenciar, intencionalmente e sistematicamente, formas construtivas de interação social, adquirindo saberes éticos que lhe propiciem condições para o exercício da cidadania (Gonçalves, 2004). Para esta autora, a educação moral está relacionada à formação de indivíduos críticos e participativos, a qual passa pela formação de uma consciência moral, componente constitutivo do agir moral. Isso implica em capacitar o aluno a interagir com base no respeito mútuo e no reconhecimento do outro como um ser social. A consciência moral deve estar fundamentada no diálogo para a solução dos conflitos inevitáveis que surgem na convivência humana, caminhando em direção a uma identidade do Eu crítica e participativa.

No entanto, a literatura tem apresentado dados preocupantes no interior da escola, já que este se revela repleto de conflitos e violência manifestados em forma de segregação, exclusão e indiferença ao outro (Salles, Silva, Castro, Villanueva e Bilbão, 2008). Na maioria das vezes, ao pensarmos em violência, remetemo-nos unicamente a agressões físicas e/ou agressões verbais, entretanto os referidos autores destacam algumas formas de atos violentos que podem ser encontrados no cotidiano escolar como a exclusão social, a deslegitimação da política e das institui- ções sociais, as ideologias autoritárias, as dificuldades de definição e percepção do futuro e os preconceitos, discriminações e estigmas desencadeados pelos estereótipos do adulto sobre a criança ou adolescente.

Então, questionamos: como pode a escola estar pautada em uma postura que valorize condutas éticas dos alunos se não estiver comprometida em formar pessoas que manifestem ações tipicamente exemplares no que se refere às atitudes éticas e morais? É necessário que a escola defina claramente que tipo de sociedade e de ser humano deseja formar, estimulando ações essencialmente pautadas nas relações de convivência fundadas em princípios morais.

Palmieri e Branco (2007) corroboram com tal preocupação na medida em que questionam o nível de consciência dos professores quanto ao tipo de padrão de interação social que estão estimulando e promovendo entre seus alunos, posto que o estudo realizado com professores de Educação Infantil revelou que, ao invés de os professores oferecerem aos alunos uma ampla gama de atividades que poderia favorecer desde o desenvolvimento da autonomia, vivências lúdicas de competição e, especialmente, práticas cooperativas e de solidariedade, identificaram-se atividades que terminaram por fortalecer o ideário competitivo e individualista de nossa sociedade. Isso conduziu os autores a concluir que o dinamismo das práticas sociais e pedagógicas está relacionado às crenças e valores que as constituem, apontando, assim, para perspectivas de ensino-aprendizagem que não se restrinjam ao campo do desenvolvimento cognitivo desprovido de valores morais.

Ao abordar temas em torno da fundamentação dos valores morais e a educação moral pelo olhar da educação, Goergen (2005) destaca que, apesar de haver discursos por parte de diretores e coordenadores, na escola, comprometidos com a relevância da ética para o agir educativo, o que se constata é que a ética está ocupando um lugar bastante insignificante, muitas vezes restrito a um recorte disciplinar ou a uma atividade transversal.

Um estudo realizado por Dias (2005) com educadoras infantis ressalta a compreensão das inter-relações concepções/práticas como fator importante, na medida em que os educadores constroem conceitos próprios que auxiliam a sedimentação de suas práticas educativas.

Por tratar-se de sujeitos concretos, os educadores infantis vivenciam as contradições culturais inerentes às suas próprias histórias pessoal, familiar e profissional em relação ao trabalho educativo e trazem, para o processo de educar ideias, crenças e concepções que representam suas próprias visões de mundo, de homem, de sociedade e de educação (Dias, 2005, p.03).

Os fundamentos epistemológicos que nutrem a educação moral precisam ser considerados, na escola, como um processo aberto, de reflexão, discussão e legitimação de valores justos e corretos como forma de subsidiar o trabalho dos professores e, assim, integrar condutas que possam ser 
testemunhadas pelas crianças e experienciadas por meio de práticas educativas.

Nesse sentido, Oliveira (2005) reforça que a verdadeira educação ética é plantada a partir da vivência do exemplo dos conceitos éticos e na prática diária. Assim, torna-se incoerente a escola propor projetos que visem à substituição de hábitos individualistas por hábitos cooperativos se não demonstrar como o espaço escolar, orientado pedagogicamente por atitudes compartilhadas, pode desenvolver uma educação fundada na solidariedade em relação ao outro e na celebração da amizade.

Ressaltamos que o papel de formação de caráter e preparação do cidadão não se constitui meramente na escola, mas integrada a ela está a família, a roda de amigos, o grupo religioso e outros grupos sociais, visto que o homem educa-se no convívio com os outros em diferentes espaços sociais. Assim, a capacidade de reflexão, o exercício da crítica, a autonomia, a liberdade de escolha e outras qualidades desejáveis alteram-se de acordo com os contextos relacionais constituídos pelos homens (Oliveira, 2001).

Para Goergen (2007), a educação moral não se apresenta como tarefa exclusiva dos pais e da escola, mas como compromisso entrelaçado da sociedade como um todo e de suas instituições, sejam elas políticas, jurídicas, midiáticas ou educacionais. Reconhecemos, conforme o autor, que a educação moral não pode ser papel exclusivo dos pais e da escola, porém destacamos o papel da escola como agente decisivo na formação de sujeitos morais e éticos, ou seja, como um espaço que deve contribuir para a formação de um sujeito consciente e autônomo, capaz de tomar decisões, preservando tanto interesses individuais quanto sociais (Goergen, 2005, 2007).

\section{Justiça e Educação Moral}

O juízo moral, segundo Piaget (1994), desenvolve-se progressivamente, de acordo com o processo de maturação da criança. O espírito de punição realizado pelas crianças apresenta fases que acompanham os estágios da moralidade. Ele considera dois tipos de justiça, retributiva e distributiva, que estão associadas, respectivamente, à coação do adulto e à necessidade de igualdade. Ou seja, a primeira refere-se à moral heterônoma, de modo que a criança não julga pela intencionalidade do ato, e a segunda refere-se à moral autônoma, de modo que a criança passa a considerar a intenção em que um dado ato é vivido.

Sales (2000), a partir de um estudo realizado com crianças e adolescentes, reforça que a criança primeiramente responde às questões guiadas pelos resultados aparentes dos atos ou por sua conformidade às regras e, posteriormente, avança para a análise das intenções. Sampaio, Camino e Roazzi (2007) também apontam que a utilização de julgamentos equitativos torna-se cada vez maior à medida que a idade das crianças avança. Os resultados encontrados nos estudos de Dell'Aglio e Hutz (2001) corroboram com a sequência evolutiva de níveis no desenvolvimento dos princípios de justiça distributiva, apoiados pelo modelo piagetiano, sendo assim, as crianças menores utilizaram como princípios de justiça, principalmente, a autoridade e a igualdade, as de nove a dez anos preferiram a igualdade e os adolescentes, a equidade.

Isso nos leva a acreditar que o processo de formação moral do sujeito deve considerar as fases de maturação que dão sentido aos níveis de julgamento que a criança desempenha. Com isso, não queremos dizer que a criança pequena (até os sete anos) envolvida num ambiente social cooperativo não possa igualmente se apropriar moralmente de condutas cooperativas e construir juízos morais em níveis progressivos. Pelo contrário, acreditamos que é necessário instigar formas superiores de justiça, conduzindo a criança a perceber a intenção em que o ato foi presidido e contribuindo na formação de sujeitos cooperativos, justos e respeitosos com o semelhante.

Diante da crise de valores que a sociedade brasileira vem enfrentando, fica evidente a necessidade de investir em práticas educativas que focalizem a formação moral dos sujeitos. A formação moral implica na apropriação de valores que conduzem à construção do juízo moral. No entanto, parece até contraditório defender projetos escolares que visem à formação do juízo moral das crianças, já que identificam-se diversas ocorrências de injustiça no cotidiano da escola por parte dos gestores. Beluci e Shimizu (2007) revelaram injustiças do professor ao aluno; injustiça entre os alunos; injustiças sociais no âmbito educacional; direção e/ou coordenação como agentes de injustiça; injustiças da polícia para com os alunos; injustiças dos alunos em relação aos professores; injustiças dos pais com a escola e da escola com os pais; o uso de drogas ilícitas na escola; e injustiças dos alunos em relação à escola. Apesar desses dados catastróficos e contraditórios ao que desejamos para o contexto escolar, os autores, por outro lado, reforçam a necessidade de uma intervenção eficaz no sentido de propiciar relações mais justas no espaço escolar, que assegurem uma maior harmonia das mesmas, o respeito mútuo, a confiança e a autonomia das pessoas envolvidas, ou seja, eles conclamam por práticas educativas que visem a experiências compartilhadas, possibilitando os sujeitos avançarem para níveis superiores de justiça.

Para Columa (2007), a cultura da violência que se instala progressivamente na escola atual, a qual está associada à exclusão social, a altos índices de desemprego e falta de oportunidades de ascensão, enfraquece os alicerces da escola e desnorteia seu rumo. Para a autora, a violência encontrada na escola é reflexo da crise de valores (morais, éticos, humanísticos) que o Brasil e o mundo em geral atravessam.

Desse modo, os alunos devem ser incentivados à construção da autonomia moral, do desenvolvimento de níveis morais mais elevados e, consequentemente, de uma noção ideal de justiça, mediada por princípios éticos universais e caracterizada pela igualdade ou equidade da sanção e repartição igualitária entre direitos e deveres e pelo reconhecimento da complexidade das circunstâncias locais, das 
necessidades e capacidades dos envolvidos e da realidade social geral (Beluci \& Shimizu, 2007).

Os conteúdos que definem a moral são a justiça, a dignidade e a generosidade. Nesse sentido, a virtude é um valor que contribui na construção da identidade do sujeito e autorrespeito, havendo correspondência entre os julgamentos morais e as representações que os sujeitos têm de si (Tognatta \& La Taille, 2008).

Destaca-se a generosidade como virtude essencial no universo moral da criança (La Taille, 2006; Montenegro, 2005), uma vez que se torna presente no início da gênese da moralidade, bem como ocupa lugar de destaque no início da vida moral infantil. Os estudos revelam que a generosidade é melhor assimilada do que a justiça e, portanto, integrada à consciência moral nessa fase de desenvolvimento. Atribuise tal afirmação ao fato de a generosidade estar menos relacionada às imposições de autoridade do que às regras de justiça e mais a relações sociais simétricas despertadas pela simpatia, como produto de uma construção mais autêntica, posto que é decorrente de relações de cooperação (La Taille, 2006). Vale e Alencar (2008) corroboram com o autor na medida em que a generosidade faz parte do universo moral de crianças e adolescentes e, além disso, ressaltam que, embora os sujeitos considerem a ausência de generosidade merecedora de punição, já que julgam como reprovável, não indicam a punição como consequência dessa falta.

Compreendemos que a escola deve passar por um processo constante de autorreflexão e, assim, visualizar práticas educativas que contribuam na transformação do comportamento humano, valorizando a autonomia, a convivência compartilhada e o respeito para com os semelhantes. Desse modo, percebemos a escola como um espaço que pode contribuir para a reflexão e vivência de novas formas de justiça, conduzindo as crianças a uma educação permeada por princípios morais, pautada em um paradigma teórico do desenvolvimento moral e em uma revisão crítica dos modelos comumente utilizados na educação moral (Montenegro, 2005).

No que se refere ao processo de educação moral, Goergen (2007) estabelece fundamental relação entre a liberdade e a justiça, visto que a liberdade é condição essencial à moralidade, o que significa que a ação moral tem como pressuposto a livre escolha do sujeito. Desse modo, a tarefa da escola é estimular, a partir de práticas educativas, os sujeitos desejarem ser sujeitos morais.

A liberdade é condição seminal de qualquer moralidade, uma vez que sem liberdade não há decisão nem ação moral, e justiça é condição antropológica do ser humano como ser social, que precisa encontrar formas de convivência em que direitos e deveres se equilibrem. Por isso, formar sujeitos morais não significa, pelo menos não significa apenas, transmitir esse ou aquele valor, exigir esse ou aquele comportamento, mas contribuir para tornar o indivíduo um sujeito crítico, político, reflexivo. Compete ao professor despertar nos seus alunos o desejo de ser um sujeito moral. Esse é fundamentalmente um processo dialógico, argumentativo, de convencimento. Ninguém pode obrigar alguém a ser um sujeito moral contra a sua vontade, nem mesmo mediante as mais severas ameaças ou sanções, pela simples razão de que a liberdade é condição sine qua non da moralidade (Goergen, 2007, p.08).

A moralidade envolve uma interconexão entre as dimensões individual e social, revelada pelas condutas e ações humanas. Isso significa que a resposta moral dada pelos sujeitos está condicionada às escolhas e decisões sobre como agir. Tais decisões são mediadas por aspectos externos e internos, ou melhor, pela dimensão pessoal e social, concomitantemente, de forma livre, consciente e responsável, ou seja, por um agir autônomo (Dias, 2005).

Nessa perspectiva, a moralidade está associada ao sistema de regras que conduzem as condutas, valores e ações inseridas numa dada cultura ou sociedade. No entanto, o cumprimento às regras e normas é condição suficiente para constituir um indivíduo como correto, mas não para torná-lo um sujeito moral. Ninguém se forma sujeito moral por obrigação, mas sim por desejo, por reconhecer em determinada regra um significado moral. Compete à escola despertar nos alunos o desejo de ser um sujeito moral.

Então, acreditamos que a escola pode ser um lugar de experiências compartilhadas na perspectiva da convivência digna e justa. A educação pode oferecer oportunidades significativas para os educandos, contribuindo na formação de sujeitos que primem por condutas cooperativas, justas e respeitosas. Almejamos que o leitor contemple o nosso desejo de que a escola seja um espaço indispensável na construção de um mundo social mais igualitário e tolerante, renegando discursos utópicos que fazem do presente da sociedade um futuro perdido.

\section{Referências}

Beluci, T., \& Shimizu, A. de M. (2007). Injustiças no cotidiano escolar: percepções de membros de uma escola pública. Psicologia escolar e educacional, 11(2), 353-364.

Caminha, I. de O. (2007). Desejo e lei: a escola como espaço de convivência. Em P.N. Gomes \& I. de O. Caminha (Orgs.), Aprender a conviver: um enigma para a educação (pp. 165-179). João Pessoa: Ed. Universitária/ UFPB.

Columa, E. dos S. (2007). Como educar para a paz. Psicologia escolar e educacional, 11(2), 431-433.

Daolio, J. (1995). Da cultura do corpo. Campinas, SP: Papirus.

Dell'Aglio, D. D., \& Hutz, C. S. (2001). Padrões evolutivos na utilização dos princípios de justiça distributiva em crianças e adolescentes no Sul do Brasil. Psicologia: Reflexão e Crítica, 14(1), 97-106.

Dias, A. A. (2005). Educação moral e autonomia na educação infantil: 
o que pensam os professores. Psicologia: Reflexão e Crítica, 18(3), 370-380.

Díaz-Aguado, M. J., \& Medrano, C. (1999). Construção moral e educação: uma aproximação construtivista para trabalhar os conteúdos transversais (O. Fonseca, Trad.). Bauru, SP: EDUSC.

Estêvão, C. V. (2008). Educação, conflito e convivência democrática. Ensaio: Avaliação e Políticas Públicas em Educação, 16(61), 503513.

Fischmann, R. (2007). Injustiça, autonomia moral e organização escolar: análise exploratória de relações. Paideia (Ribeirão Preto), 17(38), 321-330.

Goergen, P. (2001). Educação Moral: adestramento ou reflexão comunicativa? Educação e Sociedade, 22(76), 147-174.

Goergen, P. (2005). Educação e valores no mundo contemporâneo. Educação e Sociedade, 26(92), 983-1011.

Goergen, P. (2007). Educação moral hoje: cenários, perspectivas e perplexidades. Educação e Sociedade, 28(100), 737-762.

Gonçalves, M. A. S. (2004). Identidade do eu, consciência moral e estágios do desenvolvimento: perspectivas para a educação. Psicologia da Educação, 19, 73-89.

La Taille, Y. de. (2006). A importância da generosidade no início da gênese da moralidade na criança. Psicologia: Reflexão e Crítica, 19(1), 9-17.

Montenegro, T. (2005). Educação infantil: a dimensão moral da função de cuidar. Psicologia da educação, 20, 77-101.

Oliveira, M. C. K. (2005). Por uma ética da convivência. Caesura: Revista Crítica de Ciências Sociais e Humanas, 26, 53-61.

Oliveira, R. J. de. (2001). Ética na escola: (re)acendendo uma polêmica. Educação e Sociedade, 22(76), 212-231.

\section{Sobre os autores}

Glycia Melo de Oliveira (glyciam@yahoo.com.br)

Universidade Federal da Paraíba, João Pessoa - PB

Iraquitan de Oliveira Caminha (iraqui@uol.com.br)

Universidade Federal da Paraíba, João Pessoa - PB

Clara Maria Silvestre Monteiro de Freitas (clarasilvestre@gmail.com)

Universidade Federal da Paraíba, João Pessoa - PB

\section{Correspondência}

Glycia Melo de Oliveira

Av. do Catre, s/n, Cond. Ícaro Residencial, bl14, aptº102, Emaús

Parnamirim/RN CEP: 59148-520
Palmieri, M. W. A., \& Branco, A. U. (2007). Educação infantil, cooperação e competição: análise microgenética sob uma perspectiva sociocultural. Psicologia escolar e educacional, 11(2), 365-378.

Piaget, J. (1994). O juízo moral na criança. São Paulo: Summus. (Trabalho original publicado em 1932)

Rossetto, E. (2008). A educação à luz do pensamento de Maturana. Revista Educação Especial, 32.

Sales, E. da M. B. de. (2000). O conceito de justiça distributiva relacionado às normas sociais escolares. Psicologia: Reflexão e Crítica, 13(1), 49-58.

Salles, L. M. F., Silva, J. M. A. de P., Castro, J. C. R., Villanueva, C. F., \& Bilbão, R. D. (2008). A violência no cotidiano escolar. Educação: Teoria e Prática, 18(30), 15-23.

Sampaio, L. R. (2007). A Psicologia e a educação moral. Psicologia: Ciência e Profissão, 27(4), 584-595.

Sampaio, L. R., Camino, C. P. dos S., \& Roazzi, A. (2007). Justiça distributiva em crianças de 5 a 10 anos de idade. Psicologia: Reflexão e crítica, 20(2), 197-204.

Souza, V. L. T. de. (2005). Escola e construção de valores: desafios à formação do aluno e do professor. São Paulo: Edições Loyola.

Tognetta, L. R. P., \& La Taille, Y. de. (2008). A formação de personalidades éticas: representações de si e moral. Psicologia: Teoria e Pesquisa, 24(2), 181-188.

Vale, L. G. do, \& Alencar, H. M. de. (2008). Juízos morais de crianças e adolescentes sobre ausência de generosidade e punição. Psicologia: Revista da Vetor Editora, 9(2), 235-244.

Recebido em: 20/09/2009

Reformulado em: 16/09/2010 Aprovado em: 20/09/2010 